Article

\title{
New Evidence of the Enhanced Elimination of a Persistent Drug Used as a Lipid Absorption Inhibitor by Advanced Oxidation with UV-A and Nanosized Catalysts
}

\author{
Narcisa Vrinceanu ${ }^{1}$, Raluca Maria Hlihor ${ }^{2}$, Andrei Ionut Simion ${ }^{3, *}$, Lacramioara Rusu ${ }^{3, *}$, \\ Ildikó Fekete-Kertész ${ }^{4}$, Noureddine Barka ${ }^{5}$ and Lidia Favier ${ }^{6, *}$ \\ 1 Department of Industrial Machines and Equipment, Faculty of Engineering, "Lucian Blaga” University of \\ Sibiu, 2-4 Emil Cioran Street, 550024 Sibiu, Romania; vrinceanu.narcisai@ulbsibiu.ro \\ 2 Department of Horticultural Technologies, Faculty of Horticulture, University of Agricultural Sciences and \\ Veterinary Medicine of Iasi, 3 Mihail Sadoveanu Alley, 700490 Iasi, Romania; raluca.hlihor@uaiasi.ro \\ 3 Department of Chemical and Food Engineering, Faculty of Engineering, University of Bacau, 157 Calea \\ Marasesti, 600115 Bacau, Romania \\ 4 Department of Applied Biotechnology and Food Science, Budapest University of Technology and Economics, \\ H-1111 Budapest, Hungary; fekete.kertesz.ildiko@mail.bme.hu \\ 5 Research Group in Environmental Sciences and Applied Materials (SEMA), Sultan Moulay Slimane \\ University of Beni Mellal, FP Khouribga, B.P. 145, 25000 Khouribga, Morocco; barkanoureddine@yahoo.fr \\ 6 Ecole Nationale Supérieure de Chimie de Rennes, Univ Rennes, CNRS, ISCR-UMR6226, \\ F-35000 Rennes, France \\ * Correspondence: asimion@ub.ro (A.I.S.); lacraistrati04@yahoo.com (L.R.); lidia.favier@ensc-rennes.fr (L.F.); \\ Tel.: +33-223-238-135 (L.F.)
}

Received: 8 August 2019; Accepted: 5 September 2019; Published: 11 September 2019

\begin{abstract}
This work demonstrates new evidence of the efficient destruction and mineralization of an emergent organic pollutant using UV-A and titanium nanosized catalysts. The target compound considered in this work is the primary metabolite of a lipid regulator drug, clofibrate, identified in many studies as refractory during conventional wastewater treatment. The photocatalytic performance study was carried out in batch mode at laboratory scale, in aqueous suspension. Kinetic data showed that titanium dioxide P25 Aeroxide ${ }^{\circledR}$ exhibits the highest photocatalytic efficiency compared to the other investigated catalysts. Pollutant degradation and mineralization efficiencies strongly increased when decreasing the initial substrate concentration. Target molecules oxidized faster when the catalyst load increased, and the mineralization was enhanced under acidic conditions: $92 \%$ of mineralization was achieved at $\mathrm{pH} 4$ after 190 min of reaction. Radical quenching assays confirmed that $\mathrm{HO}^{\bullet}$ and $\left(\mathrm{h}_{\mathrm{vb}}^{+}\right)$were the reactive oxygen species involved in the photocatalytic oxidation of the considered pollutant. In addition, further results revealed that the removal efficiency decreased in real water matrices. Finally, data collected through a series of phytotoxicity tests demonstrated that the photocatalytic process considerably reduces the toxicity of the treated solutions, confirming the process's effectiveness in the removal of persistent and biorefractory emergent organic water pollutants.
\end{abstract}

Keywords: emerging water pollutants; pharmaceutic compounds; titania catalysts; photocatalysis; kinetics; degradation; mineralization; toxicity 


\section{Introduction}

In a global environmental context, the formulation of novel synthetic pharmaceuticals is sadly associated with their misuse. These molecules are detected in water bodies, effluents of wastewater treatment plants (WWTPs), and even in drinking water in very low concentrations (low ppb levels); as a consequence, they are considered an important class of emergent water pollutants [1-4]. For example, numerous scientific reports indicate the presence of acidic drugs in wastewater treatment plants, as well as in surface water and groundwater [1]. For instance, clofibric acid (CA) represents this class of molecules, as well as ibuprofen, diclofenac, ketoprofen, or acetylsalicylic acid. It is the first active metabolite of clofibrate and the active principle of blood lipid regulators, sharing a common functional group (i.e., carboxyl group) and similar pKa with acidic drugs [1]. Its biological effects are not yet thoroughly understood, but it was associated with endocrine disruption through interference with cholesterol synthesis $[1,5]$. Nevertheless, according to the present European legislation on the classification and labeling of chemicals (92/32/EEC), CA has been reported to be a nonhazardous substance.

This metabolite's widespread presence in WWTPs is due to its continuous consumption in developing countries (from 1-2 g/day up to thousands of tons/year) and its high resistance to degradation due to its complex structure [1,4]. Moreover, it is recognized as recalcitrant to conventional technologies used for wastewater treatment and as one of the most persistent (estimated at more than 21 years) drugs found in the aquatic system [6-8]. Hence, several works report that this emergent pollutant is commonly found during environmental monitoring studies at concentration levels up to $1.1 \mu \mathrm{g} / \mathrm{L}$ in surface waters [5,8], within the range of $\mathrm{ng} / \mathrm{L}$ to $\mu \mathrm{g} / \mathrm{L}$ in the effluents of wastewater treatment plants, and up to $270 \mathrm{ng} / \mathrm{L}$ in drinking and tap water $[1,9,10]$. Furthermore, many studies have recognized the effluents of WWTPs as one of the major sources of surface water contamination with since this molecule's elimination by the conventional technologies remains very limited $[6,7,11]$. Hence, it is compulsory to develop and manage new advanced processes to completely remove persistent organic pollutants from water and wastewater in order to prevent their release into the aquatic environment.

For the removal of pharmaceuticals and acidic drugs such as CA metabolites, several physicochemical water treatment procedures were investigated, e.g., coagulation, adsorption through granular activated carbon [12,13], sedimentation, or filtration [14]. However, the main disadvantage of these techniques is that they transfer the pollutant from one phase to another but do not completely remove it through a mineralization mechanism. In this framework, the use of a complementary treatment such as advanced oxidation processes (AOP) could be an efficient way to eliminate pharmaceutical products from polluted waters due to the strong oxidant abilities of hydroxyl radicals. Some of these techniques were investigated for their ability to eliminate this refractory organic molecule. For example, it was reported that ozonation or catalytic ozonation could be interesting options for the degradation of clofibric acid because of their powerful oxidation abilities. However, it was found that the ozone alone could only partially mineralize this molecule, while homogeneous catalytic ozonation generates secondary pollution such as metal-containing sludge $[15,16]$. Moreover, other researchers found that CA is also poorly eliminated through ozonolysis [17] and UV photolysis [18]. Up to now, Fenton-like reactions [19], photoelectro-Fenton and electro-Fenton [20,21], $\mathrm{UV} / \mathrm{H}_{2} \mathrm{O}_{2}$ [22,23], and anodic oxidation [21] have also been applied for CA elimination. Among the AOP techniques, heterogeneous photocatalysis has emerged over the last decade as an attractive technique for water and wastewater purification, and numerous works have proved its effectiveness in the elimination of several pharmaceutic compounds such as carbamazepine, iomeprol, sulfamethoxazole, iopromide from natural water, and wastewater [24-27].

To the best of our knowledge, only a few studies are available in the literature on the photocatalytic elimination of this molecule. The main advantage of photocatalysis is that it leads to the transformation of the parent compounds by oxidation in biodegradable intermediates or their complete mineralization (transformation in carbon dioxide and water). This technique involves the generation of an $\mathrm{e}-\mathrm{h}+$ pair, 
which leads to the formation of reactive species such as hydroxyl radicals and superoxide anions in the presence of photons having energy equal to or higher than that of their band-gap energy [28].

Keeping in mind all this information, the main goal of this work was to investigate the efficiency of the photocatalytic treatment in the elimination of the persistent and biorefractory metabolite of clofibrate, a drug frequently used in the treatment of coronary disease, blood pressure, and arrhythmia. Our study provides an insight into the systematic evaluation of the photocatalytic kinetics under different operating conditions such as catalyst type, catalyst load, initial pollutant concentration, initial solution $\mathrm{pH}$, and water matrix to enhance the degradation and mineralization degree of the target molecule, clofibric acid. In addition, the influence of some radical scavengers was studied to achieve a deeper understanding of the mechanism that governs the photodegradation of this molecule. Finally, the feasibility of the photocatalytic process was assessed in terms of toxicity elimination through ecotoxicity tests using two higher plants. This study provides complete knowledge and new evidence on the performance of UV-A photocatalysis in the elimination of emergent water pollutants, opening new ways for the development of environmentally safe technologies for water purification.

\section{Results and Discussion}

\subsection{Catalyst Screening}

In this work, we have investigated the photocatalytic activity of three commercial titanium dioxide catalysts (P25 Aeroxide ${ }^{\circledR}$, Acros Organics, Geel, Belgium; Kronos uvlp 7500, Kronos Europe S.A./N.V., Ghent, Belgium; Cristal PC 500, Cristal, France SAS) to select the most efficient one for the removal of the target molecule. For these studies, the photocatalytic experiments were conducted at an initial pollutant concentration of $30 \mathrm{mg} / \mathrm{L}$, a catalyst dose of $1 \mathrm{~g} / \mathrm{L}$, and a maximal light flux of $9.52 \mathrm{~mW} / \mathrm{cm}^{2}$. Many studies showed that the degradation kinetics of different organic pollutants can be described by the pseudo-first-order kinetics (Equation (1)):

$$
-\frac{d C_{p}}{d t}=k_{a p p} \cdot C_{p}
$$

where $\left(k_{\text {app }}\right)$ is the apparent first-order constant. $\left(C_{p}\right)$ is the pollutant concentration after a reaction time $(t)$.

The integration of Equation (1) leads to Equation (2):

$$
-\ln \frac{C_{p}}{C_{0}}=f(t)
$$

assuming that $C_{p}=C_{0}$ at $t=0$.

The results for the degradation kinetics (plots of $-\ln C_{p} / C_{0}$ versus irradiation time) of the target molecule in the presence of the investigated catalysts are presented in Figure 1. According to the kinetic data, pollutant degradation follows the pseudo-first-order kinetics and the obtained regression coefficient for the linear fitting for each case was greater than 0.99 .

Data analysis clearly shows that P25 Aeroxide ${ }^{\circledR}$ exhibits the highest photocatalytic activity for the degradation of clofibric acid compared to the other investigated catalysts. Indeed, for this catalyst, the degradation rate constant calculated for the first $130 \mathrm{~min}$ of reaction was higher $\left(0.0152 \mathrm{~min}^{-1}\right)$ than the one obtained for the other commercial titanium dioxides $\left(0.0052 \mathrm{~min}^{-1}\right.$ for Kronos uvpl 7500 and $0.0026 \mathrm{~min}^{-1}$ for PC 500, respectively). It must be noticed that control experiments under identical conditions were also carried out in the dark to evaluate the adsorption of the target molecule on the considered catalysts, and the collected data from the dark period clearly showed a very low (less than $5 \%$ for each) adsorption extent for clofibric acid (data not shown). Moreover, under the investigated photocatalytic conditions, a high removal yield of about $86 \%$ was observed after an irradiation time of 130 min using P25 Aeroxide ${ }^{\circledR}$ as a catalyst. For the other catalysts evaluated, the obtained values were significantly lower than the ones determined for P25 Aeroxide ${ }^{\circledR}$. An elimination yield of $49 \%$ was 
found for Kronos uvlp 7500 and of $29 \%$ for PC 500, respectively. In addition, the same evolution trend was observed for the mineralization efficiency (data not shown).

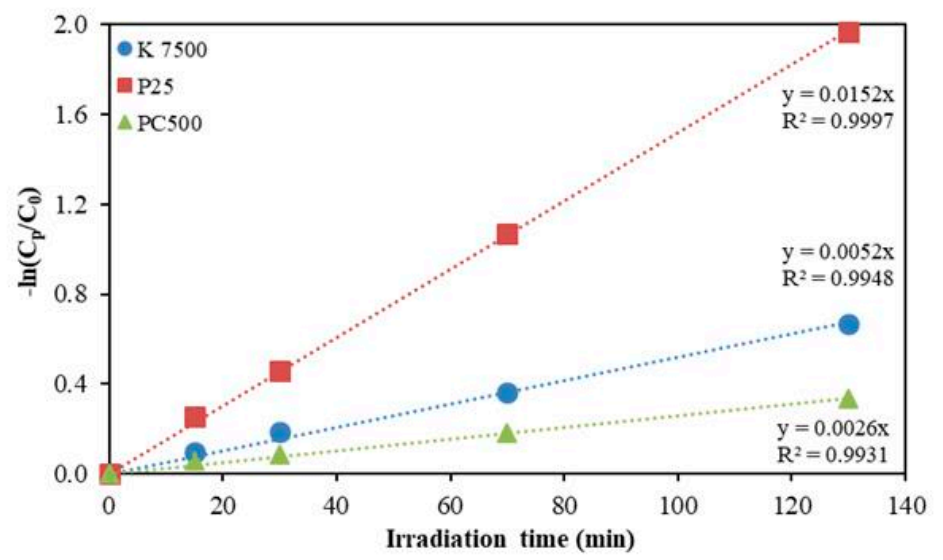

Figure 1. Degradation kinetics for clofibric acid (initial concentration $30 \mathrm{mg} / \mathrm{L}$ ) with different $\mathrm{TiO}_{2}$ commercial catalysts $(1 \mathrm{~g} / \mathrm{L}), \mathrm{UV}-\mathrm{A}$ irradiation $\left(9.52 \mathrm{~mW} / \mathrm{cm}^{2}\right)$, natural solution $\mathrm{pH}$, room temperature.

Similar results were obtained by Xekoukoulotakis et al. [29] for the degradation of the antibiotic sulfamethoxazole in aqueous solution under UV-A irradiation. Moreover, our results are in agreement with the ones previously reported by Bahnemannn et al. [30], Hapeshi et al. [31], and Fotiou et al. [32] for the photodegradation of other organic molecules.

According to the literature, the greater photocatalytic activity of P25 Aeroxide ${ }^{\circledR}$ can be due to the slower rate of recombination between electrons and holes on the catalyst surface $[33,34]$. Other researchers correlate this finding to the crystalline structure of this catalyst, which consists of $75 \%$ anatase and $25 \%$ rutile, and the mixture of phases is considered more effective than the individual ones (pure crystalline phases) [35]. It was also reported that the enhanced activity of $\mathrm{TiO}_{2} \mathrm{P}_{2} 5$ can be due to the small size of rutile particles and their proximity to anatase particles [36].

Based on the obtained results, we used P25 Aeroxide ${ }^{\circledR}$ in this work for further photocatalytic studies.

\subsection{Adsorption, Photolysis, and Photocatalytic Tests}

A series of experiments was initially designed to investigate the pollutant removal rate in the dark, in the presence of the selected catalyst (adsorption), in the absence of catalyst and under UV-A irradiation (photolysis), and in the presence of photocatalyst under UV-A (photocatalysis). The assays were performed at an initial pollutant concentration of $30 \mathrm{mg} / \mathrm{L}, \mathrm{pH}$ of $5.9,1 \mathrm{~g} / \mathrm{L}$ of catalyst, and a maximal irradiation $\left(9.52 \mathrm{~mW} / \mathrm{cm}^{2}\right)$. The obtained profiles of $C / C_{0}$ for clofibric acid degradation $(C$ and $C_{0}$ are the current and initial pollutant concentrations) versus the reaction time are depicted in Figure 2. A remarkable decrease in the pollutant concentration was observed in the presence of the catalyst and UV-A. Under these conditions, a removal yield of approximately $100 \%$ was found after $190 \mathrm{~min}$ of reaction. However, insignificant removal (only 5\%) was observed with UV-A light alone in the absence of a catalyst (i.e., a photolytic process). Similarly, a very little loss in pollutant was found for the adsorption experiments performed in the dark. These data are in accordance with the ones reported previously by Ziegmann and Frimmel [37] for powder-activated carbon. Similar results were found for other refractory water pollutants such as carbamazepine and chlorophenols $[26,38,39]$.

The obtained results demonstrated that the considered catalyst and irradiation (UV-A) play a remarkable role in the elimination of the target molecule, confirming that the removal efficiency could only be attributed to the photocatalytic reaction. 


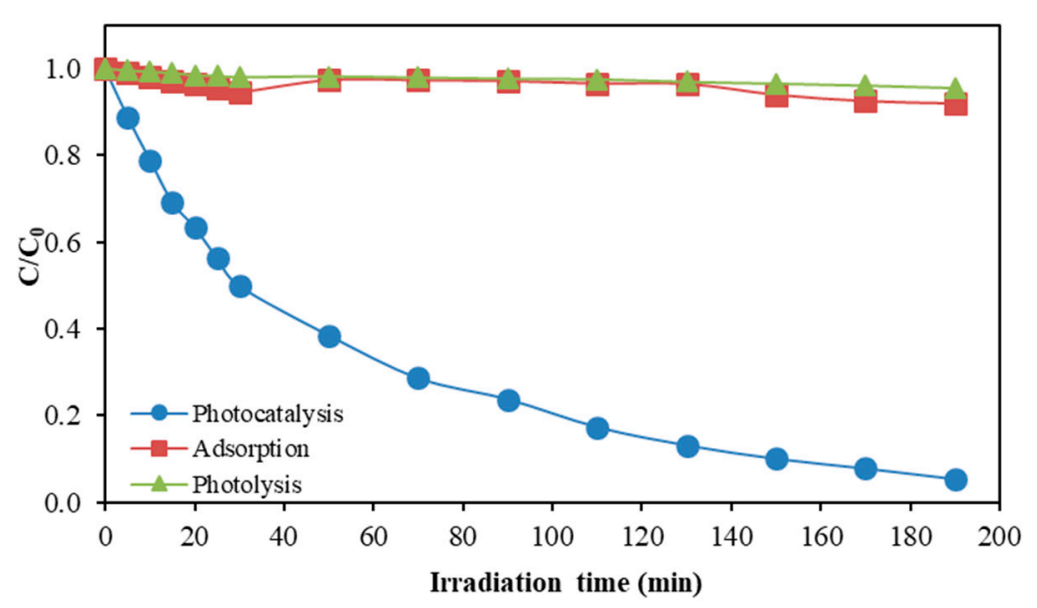

Figure 2. Pollutant removal during adsorption, photolysis, and photocatalysis. Initial clofibric acid concentration of $30 \mathrm{mg} / \mathrm{L}, 1 \mathrm{~g} / \mathrm{L}$ catalyst load, UV-A irradiation $\left(9.52 \mathrm{~mW} / \mathrm{cm}^{2}\right)$, natural solution $\mathrm{pH}$, room temperature.

\subsection{Effect of Initial Pollutant Concentration}

In a photocatalytic process, from a practical point of view, it is important to investigate the degradation efficiency as a function of the initial pollutant concentration.

The influence of the initial pollutant content on the photodegradation of clofibric acid was evaluated by varying its concentration in the range of $1.5-30 \mathrm{mg} / \mathrm{L}$, at $1 \mathrm{~g} / \mathrm{L}$ of catalyst and for a maximal irradiation flux $\left(9.52 \mathrm{~mW} / \mathrm{cm}^{2}\right)$. According to the data presented in Figure 3a, it was found that the pollutant removal increases when the amount of target molecule decreases, achieving a maximum of $93 \%$ of elimination after $30 \mathrm{~min}$ of reaction for an initial pollutant concentration of $1.5 \mathrm{mg} / \mathrm{L}$. For the highest target molecule concentration investigated in this experiment $(30 \mathrm{mg} / \mathrm{L})$, only $50 \%$ degradation efficiency was found after the same reaction time.

One of the main interests of the photocatalytic oxidation is its efficiency in destroying harmful organic pollutants and their mineralization, which generally was evaluated in terms of dissolved organic carbon elimination (DOC) [40,41]. For this reason, in this study we focused our attention on the determination of the extent of mineralization of the target molecule under the considered photocatalytic process conditions. For DOC elimination, a significant decrease was observed when the initial pollutant concentration was increased from 1.5 to $30 \mathrm{mg} / \mathrm{L}$ (Figure 3b). The maximum extent of mineralization of clofibric acid (71\%) was obtained at $1.5 \mathrm{mg} / \mathrm{L}$ of pollutant after $190 \mathrm{~min}$ of irradiation, while at $5 \mathrm{mg} / \mathrm{L}, 15 \mathrm{mg} / \mathrm{L}$, and $30 \mathrm{mg} / \mathrm{L}$, the respective values determined for this parameter were $65 \%$, $55 \%$, and $32 \%$. Moreover, it could be observed that the DOC elimination was much slower than the degradation yield. This can be due to the formation of reaction intermediates, which are more difficult to eliminate and mineralize, especially when their concentration in the reaction media is higher and the other process parameters are fixed.

For a constant catalyst load and irradiation flux, the performance of the photocatalytic process depends on the ratio between the active sites on the catalyst surface and the substrate molecules. At a low initial pollutant concentration, the active sites on the catalyst surface are in excess and can accommodate the pollutant molecules. On the contrary, as the initial concentration of the target molecule increased, the generation of reactive species such as hydroxyl radicals was reduced. This can be explained by the fact that more reactants and reaction byproducts were adsorbed on the titanium dioxide surface and, as a consequence, fewer sites remain available for their generation [42,43]. 


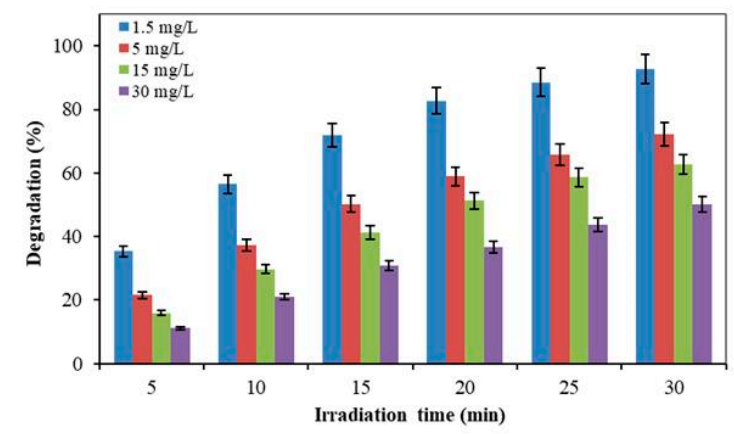

(a)

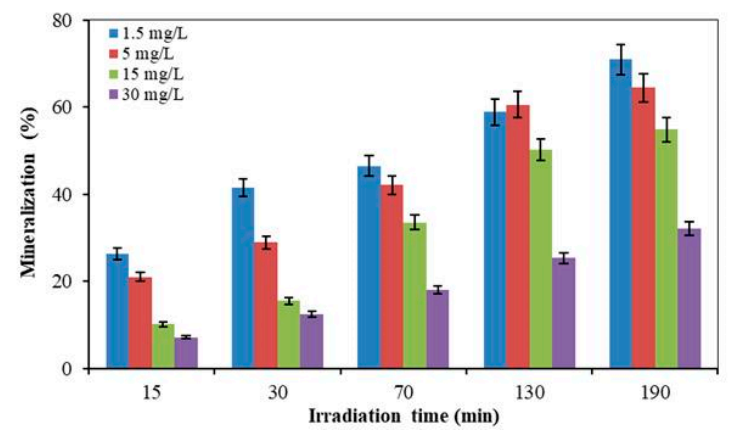

(b)

Figure 3. Effect of initial pollutant concentration on the target compound degradation (a) and mineralization (b) efficiency with $1 \mathrm{~g} / \mathrm{L}$ of catalyst, maximal irradiation $\left(9.52 \mathrm{~mW} / \mathrm{cm}^{2}\right)$, natural solution $\mathrm{pH}$, room temperature.

\subsection{Effect of Catalyst Loading}

Many photocatalytic studies reported a strong influence of the catalyst loading on the degradation efficiency for the different organic water pollutants [29,44]. Other works showed that, in a photocatalytic process, the degradation rate increases linearly with the catalyst content in the solution, because of the increases in the available surface area [45]. Silva and Faria [43] highlighted that the determination of the optimal value of this parameter is of key importance to guarantee the total absorption of photons at the catalyst surface and to avoid the scattering phenomena of UV irradiation, causing a reduction of the light path into the reaction media. This value is dependent on the reactor geometry, the operating conditions (e.g., initial pollutant concentration, light intensity, catalyst type), and also on the target molecule. It corresponds to the case when the catalyst surface is fully illuminated [29]. Generally, above the optimal catalyst concentration the degradation rate decreases because of the light-scattering effect or catalyst agglomeration.

Keeping in mind all this information, the effect of this process parameter on the photodegradation of clofibric acid $(1.5 \mathrm{mg} / \mathrm{L})$ was investigated. Several tests were carried out by varying the P25 Aeroxide ${ }^{\circledR}$ concentration in the range of $0.1-1 \mathrm{~g} / \mathrm{L}$, while keeping the other parameters constant (light intensity, $\mathrm{pH}$, and temperature). According to the results (Figure 4a), the clofibric acid removal yield increases with the catalyst load, confirming the heterogeneous catalytic regime, because the light absorbed at the catalyst surface increases with the semiconductor amount [29]. A maximum removal yield (95\%) was achieved at $1 \mathrm{~g} / \mathrm{L}$ of catalyst after $30 \mathrm{~min}$ of irradiation, whereas at $0.1 \mathrm{~g} / \mathrm{L}$ only $87 \%$ was degraded. The obtained results demonstrated the importance of the increased number of active sites and that of photogenerated oxidant species for the degradation of the target molecule.

As previously stated, for the photocatalytic oxidation, the final target is not only the effective degradation of the target molecule, but also its mineralization. Thus, the DOC removal profiles corresponding to the investigated conditions were also analyzed (Figure $4 \mathrm{~b}$ ). It appears that the pollutant mineralization efficiency decreases with respect to the decrease in the concentration catalyst in the reaction media. For the highest catalyst concentration investigated in this work, $71 \%$ of DOC was removed after 190 min of irradiation.

In their work, Xekoukoulotakis et al. [29] observed that the initial degradation rate of sulfamethoxazole was increased by increasing the Degusa P25 catalyst loading to an optimal concentration of $0.5 \mathrm{mg} / \mathrm{L}$. Further consistent results were found by Favier et al. $[26,28,39]$ for the degradation of carbamazepine and chlorophenols. Similarly, our data agree with those reported by Affam and Chaudhuri [46] for the photodegradation of the pesticides chlorpyrifos, cypermethrin, and chlorothalonil in aqueous $\mathrm{TiO}_{2}$ suspensions.

Based on the results reported above for the degradation and mineralization efficiency, we selected $1 \mathrm{~g} / \mathrm{L}$ as the catalyst concentration for our further experiments. 


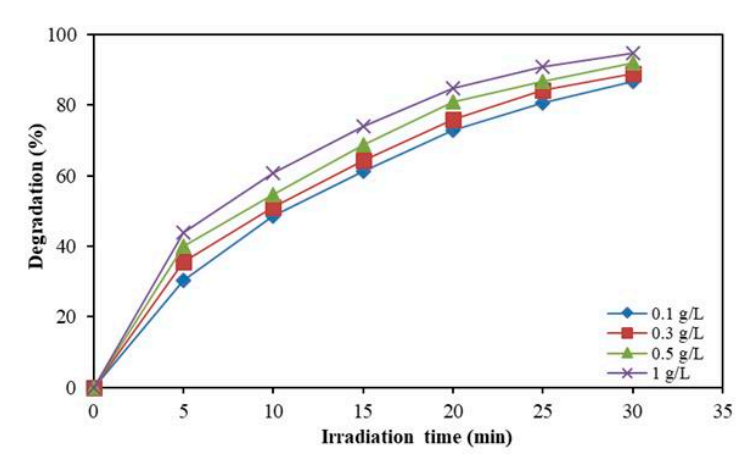

(a)

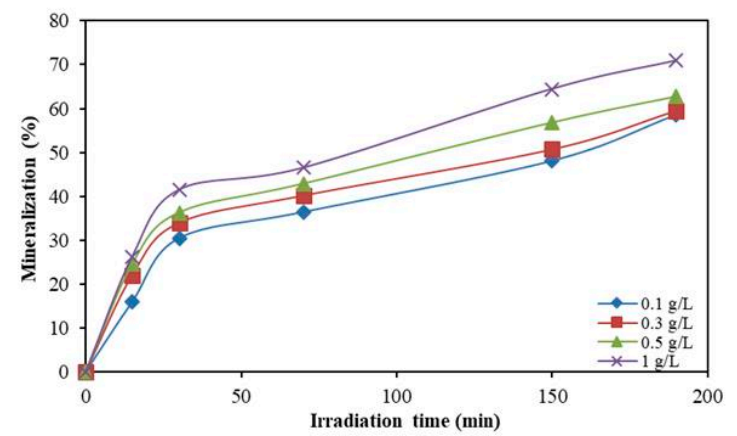

(b)

Figure 4. Effect of catalyst loading on degradation (a) and mineralization (b) efficiency of the target molecule.

\subsection{Influence of $p H$}

As the solution $\mathrm{pH}$ was recognized to affect the degradation process, some supplementary photocatalytic tests were also performed in alkaline and acid conditions in order to study the influence of this parameter. The experiments were conducted for different $\mathrm{pH}$ values in the range of $4 \leq \mathrm{pH} \leq 10$, an initial pollutant concentration of $1.5 \mathrm{mg} / \mathrm{L}$, a catalyst concentration of $1 \mathrm{~g} / \mathrm{L}$, and an incident light flux of $9.52 \mathrm{~mW} / \mathrm{cm}^{2}$. It should be noticed that the $\mathrm{pH}$ values considered in this work were close to those found for wastewaters and natural waters. For these tests, the solution $\mathrm{pH}$ was adjusted to alkaline or acidic conditions by using diluted solutions of $\mathrm{NaOH}$ or $\mathrm{HCl}(0.1 \mathrm{M})$.

The results gathered for the effect of $\mathrm{pH}$ on the removal of the target molecule are depicted in Figure 5a. It was found that the photodegradation efficiency is significantly affected by the initial solution $\mathrm{pH}$. Low $\mathrm{pH}$ conditions stimulate the pollutant elimination, which is more pronounced during the first $30 \mathrm{~min}$ of irradiation, leading to a removal of $100 \%$ and $91 \%$ at $\mathrm{pH} 4$ and 5.6, respectively. On the contrary, it was observed that alkaline conditions lead to an important decrease of the clofibric acid photodegradation efficiency. Indeed, only $64 \%$ of elimination was achieved after $30 \mathrm{~min}$ of reaction for the tests performed at an initial $\mathrm{pH}$ of 10 . On the other hand, from the DOC profiles presented in Figure $5 \mathrm{~b}$ it can been observed that the mineralization is enhanced under acidic conditions, with a mineralization degree of $92 \%$ after a reaction time of $190 \mathrm{~min}$. On the other hand, a significant decrease was achieved at $\mathrm{pH} 10$, reaching only $24 \%$ of DOC elimination for the same time of irradiation.

In their work, Gong et al. [47] reported the same $\mathrm{pH}$ effect in a systematic study carried out on the photocatalytic degradation of antipyrine. In their study, Sarkar et al. [45] highlighted that recently, some research has generalized the $\mathrm{pH}$ effect on the elimination rate, suggesting that the medium $\mathrm{pH}$ is affected by the pKa value of the considered pollutant $[29,48]$. According to these studies, the acidic medium is positive for the degradation of molecules with a lower $\mathrm{pKa}$, whereas alkaline conditions are suitable for compounds having a higher pKa value. Boroski et al. [49] also mentioned an enhancement of the degradation efficiency of a pharmaceutic molecule under acidic conditions.

It must be pointed out that the effect of this parameter in photocatalytic degradation is very complex. The explanation of its influence can be associated with the modification of the charge of the semiconductor surface, the concentration of hydroxyl radicals generated during the photocatalytic reaction, and the ionization state of the target molecule [50,51]. 


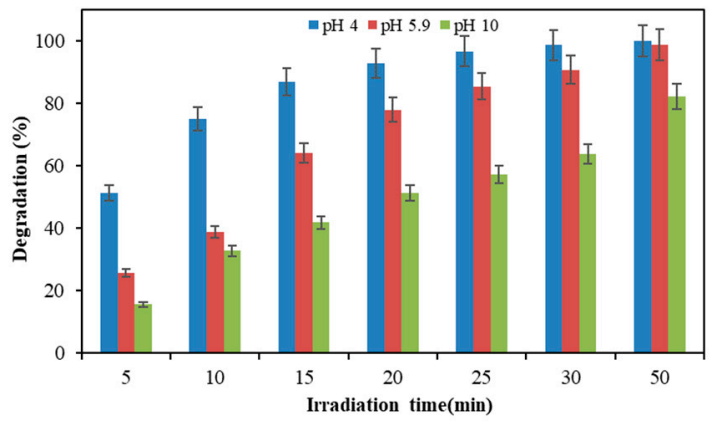

(a)

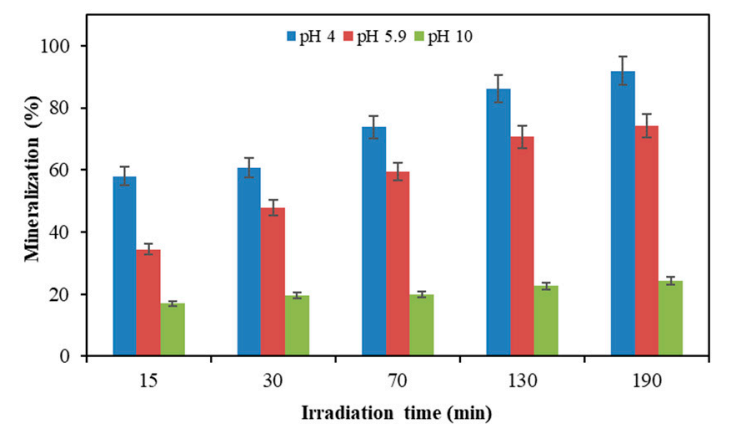

(b)

Figure 5. Effect of initial solution $\mathrm{pH}$ on the pollutant degradation (a) and mineralization (b) efficiency. Initial clofibric acid concentration of $1.5 \mathrm{mg} / \mathrm{L}, 1 \mathrm{~g} / \mathrm{L}$ catalyst load, $9.52 \mathrm{~mW} / \mathrm{cm}^{2}$, and room temperature.

Also, under acidic or alkaline conditions, the ionization state of the catalyst surface may be protonated or deprotonated according to the following equations:

$$
\begin{gathered}
\mathrm{TiO}_{2}+\mathrm{H}^{+} \rightarrow \mathrm{TiO}_{2}^{+} \\
\mathrm{TiOH}+\mathrm{OH}^{-} \rightarrow \mathrm{TiO}^{-} .
\end{gathered}
$$

For the catalyst considered in our work, the point of zero charge (PZC) was reported to be close to $6[38,52]$. Thus, the catalyst surface is positively charged in acidic conditions, while under basic conditions it is negatively charged. On the other hand, the pollutant considered in this study can be protonated or deprotonated as a function of solution $\mathrm{pH}$. Thus, it can be assumed that the results presented above may be due to a modification of the structural orientation of the considered molecule under acidic conditions, favoring its attack by reactive radicals.

Other researchers reported that, in the case of titanium dioxide Degussa P25, the phenomenon of the agglomeration of the catalyst dispersed in aqueous media decreases under acidic conditions, which leads to an increase of the effective surface area of the catalyst and may explain its enhanced activity in these $\mathrm{pH}$ conditions. Furthermore, it was pointed out that the agglomeration of catalyst is strongly influenced by the solution ionic strength. Its increase favors the agglomeration of catalyst, leading to a decrease in the effective surface area of $\mathrm{TiO}_{2}$ [29]. These findings provide another possible explanation for the results obtained in our study.

\subsection{Contribution of Some Reactive Species to the Degradation Mechanism}

It is well known that in a photocatalytic process the oxidation of pollutants is mediated by the different highly reactive oxidative species (ROS) that are generated during the reaction. The main reported ones are hydroxyl radicals $\left(\mathrm{HO}^{\bullet}\right)$, the valence band holes $\left(\mathrm{h}_{\mathrm{vb}}^{+}\right)$, and the superoxide radical $\left(\mathrm{O}_{2}^{-}\right)$. Their main specificity is that they contain atoms of oxygen, are short-lived molecules, and possess higher reactivity because of the presence of unpaired electrons undergoing reductive/oxidative reactions with persistent organic molecules [53]. In addition, beside the free radicals, reactive oxidative species also consist of nonradical species $\left(\mathrm{O}_{2}\right.$, singlet oxygen and $\mathrm{H}_{2} \mathrm{O}_{2}$, hydrogen peroxide).

As shown in the literature, previous research has been carried out to understand the mechanisms that govern the generation of these species, and to determine their role in the degradation of several organic molecules by employing selected scavengers [54,55]. Other studies indicated that their contribution to the degradation of a pollutant depends on the catalyst type used [54].

In this framework, aiming to obtain deeper information regarding the photocatalytic mechanism involved in the degradation of the target molecule in the presence of P25 Aeroxide ${ }^{\circledR}$, we focused our attention on the evaluation of the influence of some reactive species on its elimination. For this reason, 
different photocatalytic tests were conducted in the presence of selected radical scavengers such as isopropanol and methanol $(0.1 \mathrm{M})$ at an initial pollutant concentration of $1.5 \mathrm{mg} / \mathrm{L}$ and $1 \mathrm{~g} / \mathrm{L}$ of catalyst under UV-A irradiation conditions.

According to the literature data, alcohols are commonly used in photocatalytic studies as diagnostic molecules to better understand the mechanism involved in the photo-oxidation process. The major question is whether the oxidation reaction proceeds through the direct transfer between the substrate and the positive holes or via a reaction pathway mediated by the $\mathrm{HO}^{\bullet}$ radical. For example, isopropanol is recognized as an efficient $\mathrm{HO}^{\bullet}$ scavenger [56], while methanol is recognized as an inhibitor of both $\mathrm{HO}^{\bullet}$ and $\left(\mathrm{h}_{\mathrm{vb}}^{+}\right)$[57].

The obtained results for the reaction kinetics and kinetic parameters (pseudo-first-order rate constant and $R^{2}$ ), with or without the addition of $0.1 \mathrm{M}$ methanol and isopropanol, are depicted in Figure 6.

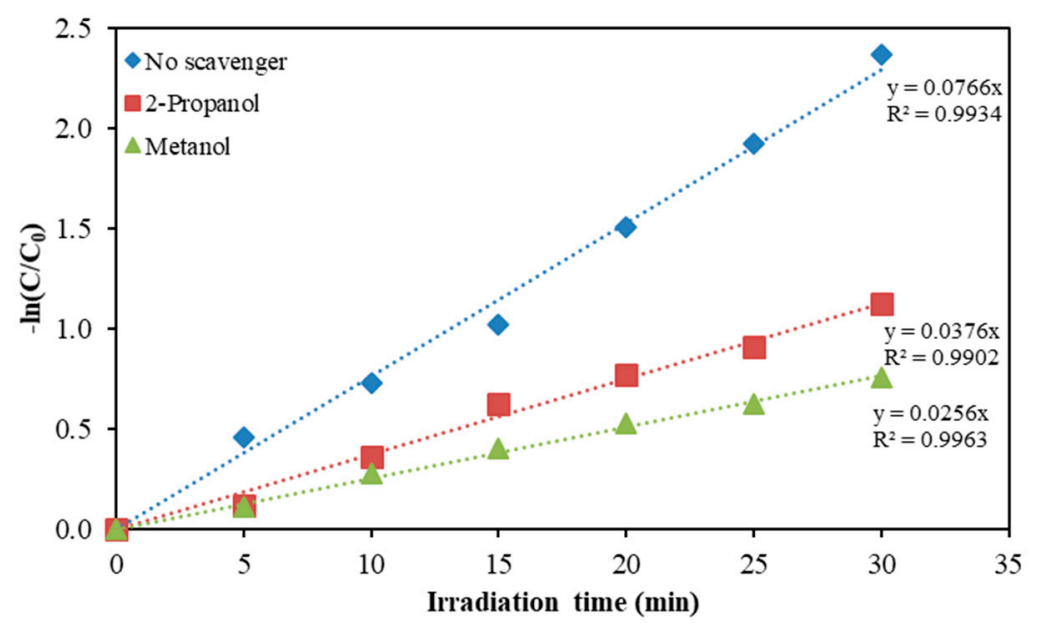

Figure 6. Photocatalytic degradation kinetics of the target molecule in the absence and presence of the selected chemical scavengers $(0.1 \mathrm{M})$. Initial clofibric acid concentration of $1.5 \mathrm{mg} / \mathrm{L}, 1 \mathrm{~g} / \mathrm{L}$ catalyst load, $9.52 \mathrm{~mW} / \mathrm{cm}^{2}$, room temperature.

It was found that the photodegradation of clofibric acid significantly decreased when isopropanol or methanol was added to the reaction media. Indeed, in the presence of a concentration of $0.1 \mathrm{M}$ of isopropanol, a strong decrease in the pseudo-first-order rate constant from $0.0766 \mathrm{~min}^{-1}$ to $0.0376 \mathrm{~min}^{-1}$ was observed, due to the inhibitory effect of this chemical. Such behavior confirms that the hydroxyl radicals dominate the oxidation of clofibric acid. However, in this study, for the investigated experimental conditions the complete inhibition of clofibric acid degradation was not achieved.

In their previous study, Antonopoulou et al. [57] consider isopropanol as an effective quencher of this radical because of its higher rate constant $\left(1.9 \times 10^{-9} \mathrm{M}^{-1} \mathrm{~s}^{-1}\right)$. Antonopoulou et al. [51], in a recent work, studied the influence of ROS on the photodegradation of three metabolites of the pharmaceutical molecule tramadol in aqueous $\mathrm{TiO}_{2}$ suspensions and noted the essential role of hydroxyl radicals in the oxidation of these transformation products.

According to Figure 6, the addition of methanol to the reaction system leads to a decrease in the calculated value for the pseudo-first-order constant rate from $0.0766 \mathrm{~min}^{-1}$ to $0.0256 \mathrm{~min}^{-1}$. A slight increase in the inhibition of the clofibric acid degradation was achieved in the presence of methanol compared to that obtained with isopropanol. The enhancement in the reaction suppression observed in the presence of methanol compared to isopropanol suggests that $\left(\mathrm{h}_{\mathrm{vb}}^{+}\right)$could be involved in the photocatalytic degradation of the target molecule. Another possible explanation is that isopropanol is more easily oxidized by hydroxyl radicals because its reaction rate constant with $H O$ is higher $\left(1.9 \times 10^{-9} \mathrm{M}^{-1} \mathrm{~s}^{-1}\right)$ compared to that of $\mathrm{MeOH}\left(1 \times 10^{-9} \mathrm{M}^{-1} \mathrm{~s}^{-1}\right)$. 
In their work, Antonopoulou et al. [51] found similar results regarding the influence of reactive species on degradation of tramadol, indicating that $h_{v b}^{+}$act as oxidants of $\mathrm{TiO}_{2}$ surface groups and water to produce $\mathrm{HO}^{\bullet}$. Chen et al. [58] and Palominos et al. [59] found similar results for the photocatalytic degradation of acid orange 7 and flumequine, respectively.

It should be noticed that supplementary adsorption experiments were carried out in the presence of methanol and isopropanol and their addition to the reaction media had a negligible influence on the adsorption of clofibric acid to the catalyst surface. Because of the low affinity of $\mathrm{MeOH}$ to the $\mathrm{TiO}_{2}$ surface, this alcohol was supposed to compete only with the hydroxyl radicals [60].

Our findings clearly confirmed that $\mathrm{HO}^{\bullet}$ radicals play an important role in the degradation of the target molecule. However, supplementary experiments are necessary to optimize the concentrations of the used alcohols to achieve total inhibition of the reaction. Additional tests in the presence of other inhibitors (iodide) are also needed to prove the involvement of holes in the degradation of clofibric acid. It is known that the valence band holes and hydroxyl radicals are efficiently blocked by $\mathrm{I}^{-}$.

\subsection{Influence of Water Matrix}

The photocatalytic tests reported up to now were carried out in ultrapure water (UW). However, from a practical point of view it is crucial to evaluate the process efficiency under experimental conditions closer to real ones. Thus, supplementary experiments were designed using two different real water samples, tap water (TW) and another from a well, and the results are presented in Figure 7.

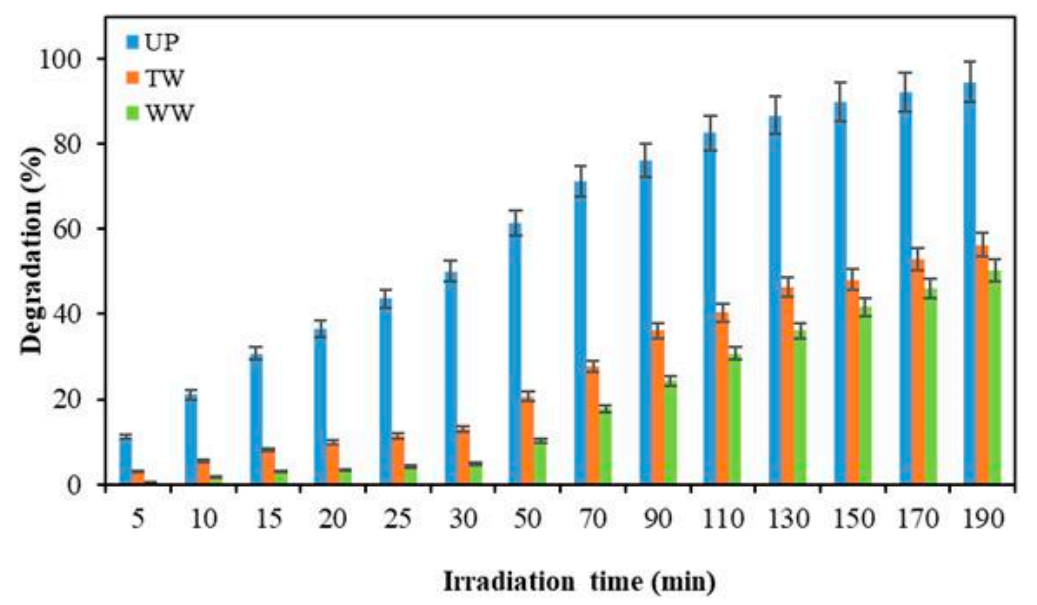

Figure 7. Effect of the water matrix on the photocatalytic degradation of clofibric acid ( $30 \mathrm{mg} / \mathrm{L} \mathrm{of}$ clofibric acid, $1 \mathrm{~g} / \mathrm{L}$ of catalyst, $9.52 \mathrm{~mW} / \mathrm{cm}^{2}$, room temperature).

In the current work, as clearly seen from Figure 7, in ultrapure water the pollutant elimination efficiency after $190 \mathrm{~min}$ of irradiation was much higher (95\%) compared to the values observed for tap water $(56 \%)$ and well water (50\%). The observed effect was not surprising. Different works highlighted that the influence of water matrix is more pronounced as the complexity of water matrix increases. More specifically, the concentration of dissolved organic carbon contained in real water samples used in this work is much higher than that contained (according to the water quality information presented in Section 3.1) in ultrapure water and, as a consequence, can react with the hydroxyl radicals and catalyst surface. On the other hand, the inorganic ions present in natural waters can act as scavengers for the reactive species generated during the photocatalytic process, leading to the formation of radical species, which are less reactive.

A strong influence of the water matrix on the photooxidation of methylparaben was previously reported by Velegraki et al. [56]. Similarly, Tsiampalis et al. [2], who studied the degradation of sulfamethoxazole with iron-doped titania, found a decrease in the degradation rate of this molecule when the reaction is conducted in secondary treated wastewater and diluted wastewater. 
Hapeshi et al. [31] also observed that the mineralization efficiency of two antibiotics, ofloxacin and atenolol, on titania suspensions and under UV-A irradiation conditions was slower in groundwater and wastewater than in ultrapure water.

The low pollutant removal yields observed in our work could be due firstly to the high initial pollutant concentration used in the photocatalytic tests, which was $30 \mathrm{mg} / \mathrm{L}$. On the other hand, the lower photocatalytic performance observed in real water samples could be ascribed to competition between the dissolved organic matter, which is naturally present in real waters, the pollutant, and the reactive species. Another explanation could be the adsorption of the organic matter on the active sites at the catalyst surface, strongly affecting its activity and as a consequence its degradation efficiency. Also, other different water components (anions or cations) can affect the pollutant degradation because they act as scavengers for radical and other reactive moieties [31].

Overall, the results obtained in our work clearly demonstrated that the nontarget compounds that are typically present in real water samples play a negative role in pollutant elimination efficiency.

\subsection{Catalyst Stability}

Catalyst stabilities studies were also performed in this work for the most efficient support (P25 Aeroxide ${ }^{\circledR}$ ). Consecutive experiments were carried out using fresh aqueous solutions of $1.5 \mathrm{mg} / \mathrm{L}$ of clofibric acid at $1 \mathrm{~g} / \mathrm{L}$ of catalyst and under maximal irradiation conditions $\left(9.52 \mathrm{~mW} / \mathrm{cm}^{2}\right)$. At the end of the photocatalytic reaction, the suspension was filtered to recover the catalyst. The support was then washed three times with ultrapure water, dried for $24 \mathrm{~h}$ at $110^{\circ} \mathrm{C}$, and reused in a new photocatalytic experiment. The results obtained through four consecutive cycles are presented in Figure 8 . The obtained results clearly show that the elimination efficiency of clofibric acid remains high (96.51\%) after three consecutive cycles. At the end of the first two cycles of catalyst reuse, a removal yield of about $98 \%$ was found. However, the catalyst activity decreases slightly during cycle 4 , with only $90.63 \%$ of degradation at the end of the photocatalytic reaction.

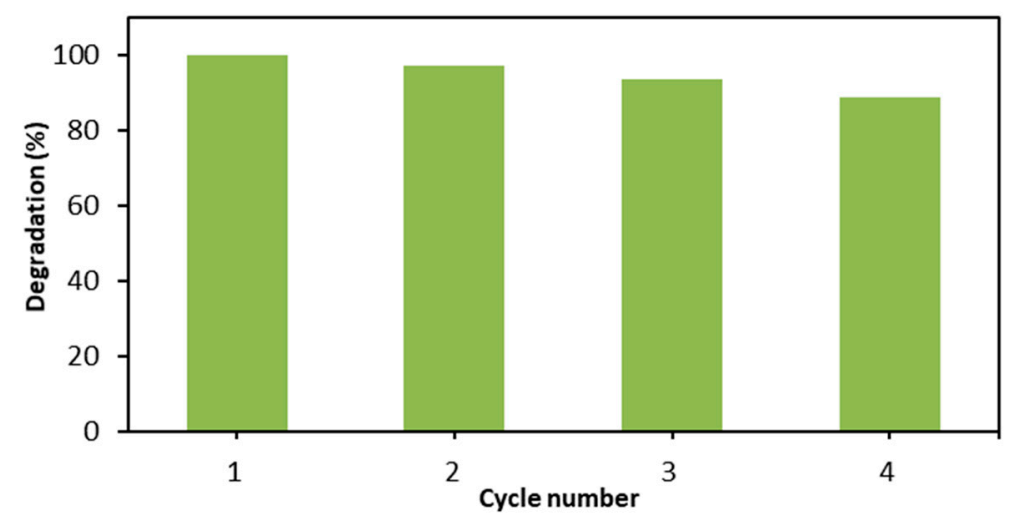

Figure 8. Pollutant removal efficiency through four successive reuse cycles of the catalyst.

The deactivation of catalyst observed during the last cycle may be due to the adsorption on its surface of some reaction intermediates that occupied the active sites, leading to a loss of photocatalytic activity. Moreover, the results collected in this work demonstrated that the selected catalyst possesses an interesting stability, showing only a small drop in its photocatalytic efficiency after four reuse cycles.

\subsection{Toxicity Evaluation}

Aiming to investigate the feasibility of the photocatalytic degradation process using the UV-A/TiO system, phytotoxicity tests were designed to assess the process efficiency in terms of toxicity elimination. During the oxidation process of an organic pollutant, the parent molecule is degraded through different chemical methods (oxidation, reduction, and addition), leading to transformation products that could be more toxic compared to the parent compound. Thus, in this work we focused on the toxicity assessment 
of the clofibric acid samples collected from the photocatalytic treatment. It was evaluated through two superior plant species, garden cress, Lepidium sativum (L. sativum), and lettuce, Lactuca sativa (L. sativa). Such plant species are usually employed in phytotoxicity studies because of their rapid germination ability and their quick root and shoot growth. Moreover, they were well known for their sensitivity when exposed to low concentrations of toxic compounds [61].

In our study, preliminary phytotoxicity experiments were carried out using the untreated solution with an initial pollutant concentration of $30 \mathrm{mg} / \mathrm{L}$ and on the samples taken at different reaction times (in the range 0-190 $\mathrm{min}$ ) from the photocatalytic treatment in the presence of $1 \mathrm{~g} / \mathrm{L}$ of catalyst and at maximal irradiation conditions. It should be pointed out that the determination of the development of roots and shoots was found to be a representative indicator to evaluate the plant growth. An overview of the obtained results related to the average lengths of roots and shoots for both investigated plant species is presented in Figure 9. It was observed that the initial solution causes an important inhibition of root and shoot growth for L. sativum as well as for L. sativa because of the high concentration of pollutant and its phytotoxicity. According to Figure 9a, a strongly inhibitory response on root growth $(60 \%)$ was found when $L$. sativum seeds were exposed to an untreated solution $(30 \mathrm{mg} / \mathrm{L}$ of clofibric acid) compared to the control. Similarly, in their study, Miglione et al. [62] reported on the negative influence of the antibiotic enrofloxacin on the postgermination of primary root growth, even at a very low pollutant concentration $(\mu \mathrm{g} / \mathrm{L})$. They showed that the exposure to a low concentration of this molecule leads to the alteration of the postgerminative development of different crop plants (Raphanus sativus, Cumicus sativus, and Lactuca sativa).

However, as shown in Figure 9 a, the presence of the pollutant causes only a minor growth inhibition effect at the shoot level. The data obtained for L. sativa showed similar behavior for the root length. In this case, the maximum recorded value for the inhibition of root growth was only about $45 \%$ (Figure 9b), which was lower than that found for L. sativum. In the absence of pollutant, which is the case with the control sample, a stimulating growth effect for the roots and shoots was observed for both considered plant species.

In addition, for the photocatalytic process it was found that the observed inhibitory effects depend on the reaction time. An increase in the adverse effect on root and shoot growth for L. sativum and L. sativa was determined for the solutions collected after an irradiation time of $30 \mathrm{~min}$, probably due to the formation of toxic reaction intermediates, and seems to be more phytotoxic for the considered seeds. Under these conditions, the root growth inhibition yielded a value of $72 \%$ and around $58 \%$ for L. sativum and L. sativa, respectively. The obtained data clearly showed a decrease in root and shoot growth inhibition with the increase in treatment time (from $30 \mathrm{~min}$ to $60 \mathrm{~min}$ ), indicating that some of the reaction intermediates are eliminated or new ones are formed, but their toxicity is much lower.

Furthermore, we could observe an insignificant adverse effect at the end of the irradiation period (190 $\mathrm{min}$ ) for both species. Such behavior is probably due to the oxidation of more toxic reaction byproducts and their transformation into less toxic ones at the end of the photocatalytic process.

Moreover, the toxic effect on root and shoot growth was not completely eliminated, even if the toxicity of the raw clofibric acid solution was strongly reduced. An increase in the reaction time is probably necessary in this case due to the high initial pollutant concentration used in this test. As previously stated, in a photocatalytic process, the degradation and mineralization efficiency strongly decrease with an increase in the initial pollutant concentration.

Furthermore, our findings clearly indicated that the inhibition effect was more pronounced in roots than for shoots for all collected samples. In their works, Fuentes et al. [63] and Rizzo [61] found similar results and reported that for the phytotoxicity tests the determination of root growth length seems to be more sensitive for the evaluation of adverse effects. On the other hand, Lofrano et al. [64] checked the toxicity of photocatalytic treated samples of the antibiotic chloramphenicol and indicated that $L$. sativum was the most sensitive testing species. 


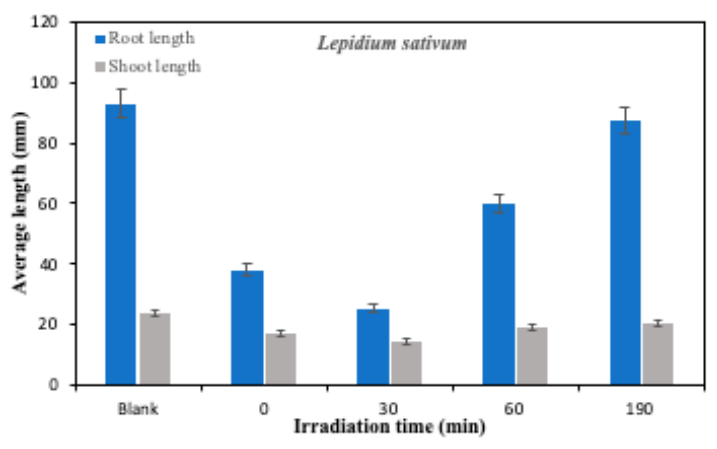

(a)

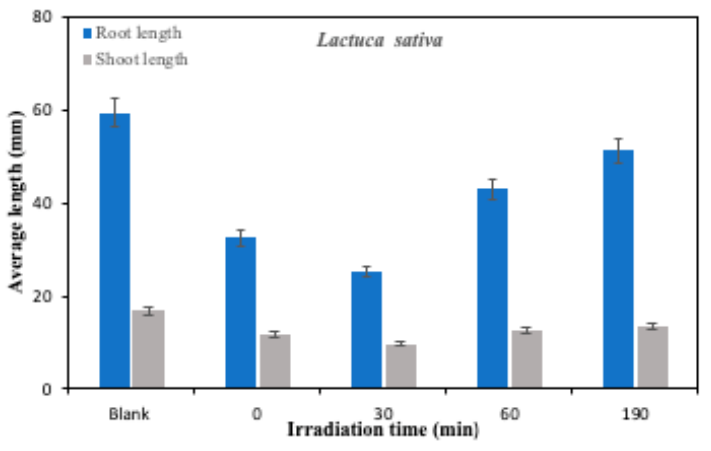

(b)

Figure 9. Average root and shoot length for Lepidium sativum (a) and Lactuca sativa (b), determined for blank, untreated, and photocatalytic treated solutions $(30 \mathrm{mg} / \mathrm{L}$ of pollutant, $1 \mathrm{~g} / \mathrm{L}$ of catalyst, $9.52 \mathrm{~mW} / \mathrm{cm}^{2}$, room temperature).

Similar evolution profiles were obtained for the calculated root tolerance index, confirming our previous data. The obtained results for both plants are depicted in Figure 10. A marked reduction in the root tolerance index compared to the control was found for the initial solution and the sample collected after $30 \mathrm{~min}$ of irradiation, probably due to their toxicity, as stated previously.

In contrast, an increase in this parameter was observed on L. sativa and L. sativum root growth for the treated samples taken after a reaction time of $60 \mathrm{~min}$ and $190 \mathrm{~min}$, respectively, confirming a reduction in the toxicity of these samples. Moreover, the value of the index determined for the sample collected at the end of the experiment $(190 \mathrm{~min})$ was not significantly different compared to that calculated for the control. Hence, such behavior suggests that, at the end of the considered treatment period, the reaction intermediates that are released are apparently less toxic than the parent compound.

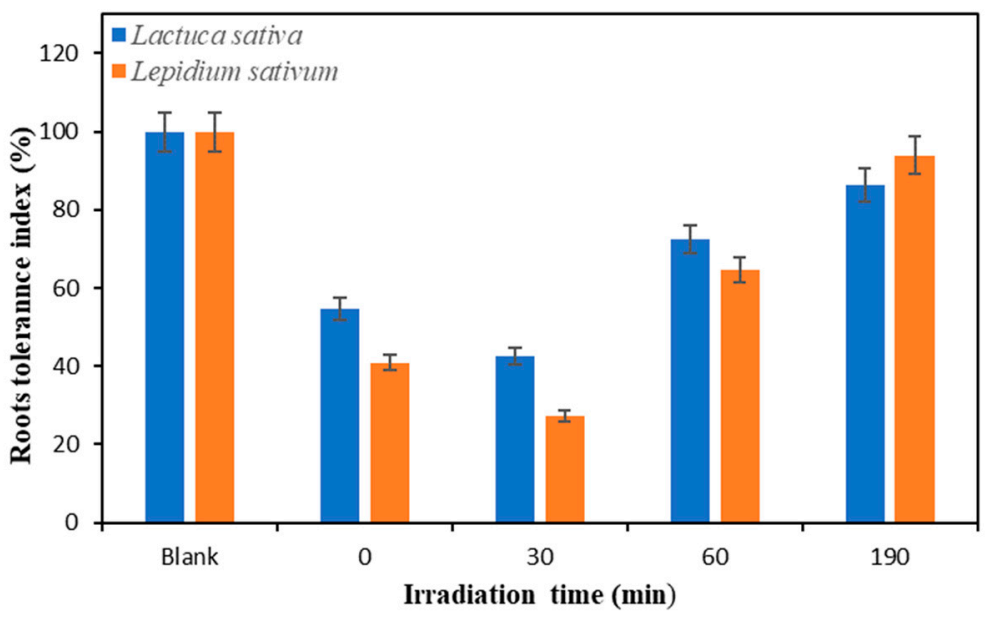

Figure 10. Evolution of the roots tolerance index during the photocatalytic treatment of clofibric acid $\left(30 \mathrm{mg} / \mathrm{L}\right.$ of pollutant, $1 \mathrm{~g} / \mathrm{L}$ of catalyst, $\left.9.52 \mathrm{~mW} / \mathrm{cm}^{2}, 26 \pm 2{ }^{\circ} \mathrm{C}\right)$.

Our results are in good agreement with those of Lofrano et al. [64] and Rosal et al. [65] for the toxicity assessment of the oxidation products generated during the photocatalytic degradation of chloramphenicol and the ozonation of clofibric acid. Furthermore, a similar conclusion could be observed for the analysis of the results obtained for the vigor index (Figure 11). 


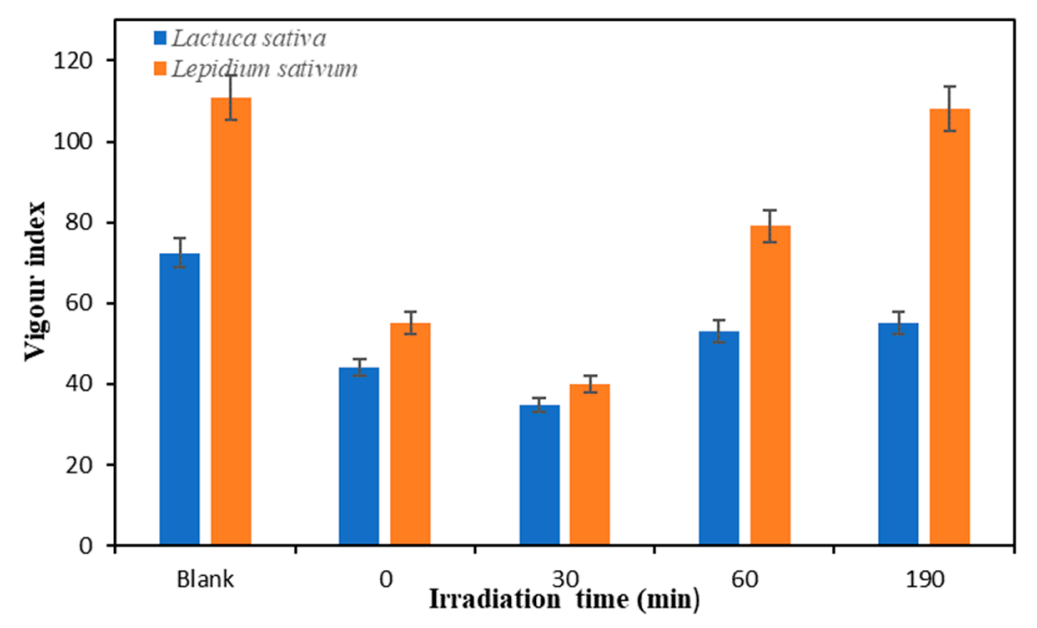

Figure 11. Evolution of the vigor index during the photocatalytic treatment of clofibric acid ( $30 \mathrm{mg} / \mathrm{L} \mathrm{of}$ pollutant, $1 \mathrm{~g} / \mathrm{L}$ of catalyst, $\left.9.52 \mathrm{~mW} / \mathrm{cm}^{2}, 26 \pm 2{ }^{\circ} \mathrm{C}\right)$.

In summary, according to our data, the seeds of both plants were affected by the presence of the target molecule and also by its photodegradation byproducts. The phytotoxicity tests used seem to be appropriate and sensitive enough for the investigation of the toxicity of the irradiated solutions of clofibric acid. The photocatalytic process's effectiveness was also confirmed by the ecotoxicity assays performed in this work with Lepidium satioum and Lactuca sativa.

\section{Materials and Methods}

\subsection{Chemicals}

Clofibric acid used in the photocatalytic studies was of analytical purity $(>99 \%)$ and obtained from Acros Organics (NJ, USA). The main physicochemical properties of the target molecule are summarized in Table 1.

Table 1. Physicochemical properties of clofibric acid.

\begin{tabular}{cc}
\hline Structure & $\mathrm{C}_{10} \mathrm{H}_{11} \mathrm{ClO}_{3}(882-09-7)$ \\
lipid regulator \\
Formula and CAS Number & 214.65 \\
Therapeutic class & 573 \\
Molecular weight $(\mathrm{g} / \mathrm{mol})$ & $2.57 \mathrm{a}$ \\
Water solubility $\mathrm{mg} / \mathrm{L}\left(25^{\circ} \mathrm{C}\right)$ & 230 \\
$\log \mathrm{Kow}$ & \\
$\lambda_{\max }(\mathrm{nm})$ &
\end{tabular}

The other chemicals (formic acid, solvents) employed in this work were supplied by Sigma Aldrich (St. Louis, MO, USA) and were of analytical grade (e.g., the highest grade commercially available) being used as received.

Working solutions for analysis and photocatalytic tests were prepared in ultrapure water (18.2 M $2 . \mathrm{cm}$ resistivity at $298 \mathrm{~K}, \mathrm{DOC}<5 \mu \mathrm{gC} / \mathrm{L} ; \mathrm{pH}=6.5$ ) produced by a water purifier system (ELGA Option-Q DV 25, Veolia, High Wycombe, UK). In addition, groundwater obtained from a well (WW) situated near to the Chemical Engineering School of Rennes (France) and tap water (TW) from the city of Rennes (France) were spiked with the target molecule and used for the photocatalytic tests to evaluate the influence of the water matrix on the photodegradation of clofibric acid. The quality 
parameters of these waters (expressed as the mean value of six individual measurements) were as follows: (i) well water: $\mathrm{pH}=8.2, \mathrm{DOC}=3 \mathrm{mg} / \mathrm{L}, 448 \mu \mathrm{S} / \mathrm{cm}$ conductivity, $65.4 \mathrm{mg} / \mathrm{L}$ chlorides, $35.2 \mathrm{mg} / \mathrm{L}$ nitrates, $50.6 \mathrm{mg} / \mathrm{L}$ sulfates; (ii) tap water: $\mathrm{pH}=7.4, \mathrm{DOC}=1 \mathrm{mg} / \mathrm{L} 570 \mu \mathrm{S} / \mathrm{cm}$ conductivity, $20 \mathrm{mg} / \mathrm{L}$ chlorides; $16.3 \mathrm{mg} / \mathrm{L}$ nitrates; $29.3 \mathrm{mg} / \mathrm{L}$ sulfates.

For the photocatalytic studies, different commercial catalysts, namely, $\mathrm{TiO}_{2} \mathrm{P} 25$ Aeroxide ${ }^{\circledR}$ (Acros Organics, Geel, Belgium); $\mathrm{TiO}_{2}$ Kronos uvlp 7500 (Kronos Europe S.A./N.V., Ghent, Belgium) and $\mathrm{TiO}_{2}$ PC500 (Cristal, France SAS) were used. Their main characteristics are presented in Table 2.

Table 2. Main characteristics of the used $\mathrm{TiO}_{2}$ catalysts according to the manufacturer's data.

\begin{tabular}{cccc}
\hline & P25 Aeroxide ${ }^{\circledR}$ & Kronos uvlp 7500 & Millenium PC-500 \\
\hline $\mathrm{TiO}_{2}$ content $(\mathrm{wt} \%)$ & $>95$ & $>85$ & 85 \\
Composition & $80 \% \mathrm{~A}, 20 \% \mathrm{R}$ & $100 \% \mathrm{~A}$ & $100 \% \mathrm{~A}$ \\
Particle size $(\mathrm{nm})$ & 21 & 15 & $5-10$ \\
Specific surface area $\left(\mathrm{m}^{2} / \mathrm{g}\right)$ & $35-65$ & $>225$ & 350 \\
Density, $20^{\circ} \mathrm{C}\left(\mathrm{g} / \mathrm{cm}^{2}\right)$ & 4.23 & 3.9 & - \\
\hline & (A-anatase; R-rutile).
\end{tabular}

\subsection{Experimental Set-Up and Photocatalytic Procedure}

Different photocatalytic tests were performed in order to evaluate the photocatalytic activity of the catalysts used and the influence of some process parameters (e.g., catalyst load, initial concentration of pollutant, light intensity, etc.) on the degradation of the target molecule. The experimental system consisted of an open cylindrical glass reactor with a total capacity of $3 \mathrm{~L}$ and a working volume of $2 \mathrm{~L}$. The device used is fully described in our previous study [26].

The reactor was artificially irradiated using two UV-A lamps (Phillips, Poland nominal power of $9 \mathrm{~W}$ ) with a spectral response in the range $320-400 \mathrm{~nm}$ and a maximum emission at $365 \mathrm{~nm}$, suitable for the activation of the catalyst. The light sources were located on the external side of the glass reactor. All tests were conducted in batch mode, at room temperature (about $20 \pm 2{ }^{\circ} \mathrm{C}$ ), with a stirring rate of $555 \mathrm{t} / \mathrm{min}$ and at a natural $\mathrm{pH}$ (corresponding to the dissolution of the target molecule in water, 5.9). In a typical photocatalytic assay, a volume of $1 \mathrm{~L}$ of CFA solution with a known concentration was loaded in a reactor containing the appropriate catalyst amount. The suspension was continuously stirred to remain homogeneous. Before starting the irradiation experiments, the lamps were preheated for $30 \mathrm{~min}$ to attain the maximum intensity and then used to initiate the photocatalytic reaction. A radiometer (VLX-3W, Vilbert Lourmat, Marne La Vallée, France) was employed to measure the photon flux per volume unit. It should be pointed out that, prior to the irradiation, the suspension was mechanically stirred in the dark for $60 \mathrm{~min}$ in order to reach the adsorption/desorption equilibria of the pollutant on the semiconductor surface. Samples were collected after the adsorption equilibrium state and prior to the irradiation, and the last point was considered as time zero for the photocatalytic degradation test.

For the study of the contribution of some reactive species (methanol and isopropanol) to the degradation mechanism, a similar procedure was employed. The investigated alcohols were added into the suspension at the beginning of the adsorption step.

The catalyst stability was also investigated by carrying out four consecutive photocatalytic tests using fresh pollutant aqueous solutions. The tests were performed for an initial pollutant concentration of $1.5 \mathrm{mg} / \mathrm{L}, 1 \mathrm{~g} / \mathrm{L}$ of catalyst $\left(\mathrm{TiO}_{2} \mathrm{P} 25\right.$ Aeroxide $\left.{ }^{\circledR}\right)$, and maximal light flux $\left(9.52 \mathrm{~mW} / \mathrm{cm}^{2}\right)$. At the end of each photocatalytic test, the catalyst was recovered by filtration, washed with ultrapure water, and then dried overnight at $110^{\circ} \mathrm{C}$.

Samples were collected at appropriate reaction times, centrifuged for $15 \mathrm{~min}$ at 10,000 rpm, and then filtered with $0.22 \mu \mathrm{m}$ syringe filters (Chromafil ${ }^{\circledR}$ Xtra H-PTFE; Macherey-Nagel, Düren, Germany) to remove the catalyst. The residual pollutant concentration in the samples was determined 
by high-performance liquid chromatography (HPLC). Dissolved organic carbon (DOC) was evaluated as described elsewhere (Section 3.3).

All experiments were carried out in duplicate and the experimental error was found to be less than $5 \%$.

\subsection{Analytical Procedures}

The residual clofibric acid concentration was monitored by high-performance liquid chromatography (HPLC) using a WATERS ${ }^{\circledR}$ system (Milford, MA, USA). Analyte separation was achieved with a reversed phase column BEH C18 $(250 \mathrm{~mm} \times 4.6 \mathrm{~mm}, 5 \mu \mathrm{m})$, and for detection a photodiode array detector (PDA; Waters TM 996, Milford, MA, USA) was employed. Elution was carried out under isocratic mode with a mixture of $60 / 40$ acetonitrile/ultrapure water containing $0.1 \%$ $(\mathrm{v} / \mathrm{v})$ of formic acid. For the analysis, an injection volume of $50 \mu \mathrm{L}$ was used and the flow rate was $1 \mathrm{~mL} / \mathrm{min}^{-1}$. The target compound detection was achieved at $227 \mathrm{~nm}$. Under these analytical conditions, the retention time of CFA was $6.2 \mathrm{~min}$. For quantification purpose, standard solutions (5.6, 10, 20, 40, 60, $80 \mathrm{mg} / \mathrm{L}$ ) were prepared in ultrapure water. For the calibration curve, the obtained correlation coefficient (R2) between the peak area and pollutant concentration was 0.998 . The instrumental detection limit (LOD) and quantification limit (LOQ) were determined based on the studies of Kadmi et al. [66,67].

Mineralization of the target molecule during the photocatalytic reaction was evaluated through the measurement of dissolved organic carbon (DOC) by direct injection using a TOC analyzer (Shimadzu TOC-5000-A, Shimadzu Corporation, Kyoto, Japan), coupled with a nondispersive IR detector. The calibration and determination of DOC were carried out as described earlier by Favier et al. [26]. $\mathrm{pH}$ measurement was performed with a $\mathrm{pH}$ meter (Cyberscan Eutech Instruments; Thermo Fisher Scientific, Singapore) and a pH probe (VWR International Europe, Louvain, Belgium; 662-1775 series).

\subsection{Phytotoxicity Tests}

Phytotoxicity tests were carried out under laboratory conditions to obtain more information on the toxicity of treated and untreated photocatalytic samples collected during the experiments. These tests were reported as a versatile tool for the evaluation of the environmental impact of pollutants present in a matrix.

In this study, for the phytotoxicity tests, two higher plant species, dicotyl garden cress (Lepidium sativum) and lettuce (Lactuca sativa), were used. Fifteen seeds from each species were placed on filter paper in a Petri dish and exposed to $3 \mathrm{~mL}$ of the sample. For comparison purposes, a control test using distilled water was also prepared. Petri dishes were incubated at $26 \pm 2{ }^{\circ} \mathrm{C}$ in the dark. Experiments were carried out in triplicate for each plant species. Root and shoot length were measured with a ruler after three days of seeds' exposure to the control solution and to the examined samples for Lepidium sativum and after seven days of exposure for Lactuca sativa, respectively. The results obtained for control and samples were evaluated in terms of the average of root and shoot lengths, root tolerance index, and vigor index, being determined according to Calvelo Pereira et al. [68].

\section{Conclusions}

The results obtained in this work indicated that the considered advanced oxidation treatment could be successfully employed to eliminate and mineralize in aqueous solution the active metabolite of the lipid regulator molecule, clofibrate.

Photodegradation experiments conducted in the presence of different semiconductors demonstrated that the degradation of the target molecule follows a pseudo-first-order kinetic model. The obtained results also proved that, among the catalysts tested, titanium P25 Aeroxide ${ }^{\circledR}$ has the highest photocatalytic performance in terms of the elimination of clofibric acid. Preliminary photolysis and adsorption experiments carried out at laboratory scale indicated that these mechanisms had a negligible influence on the removal of this pollutant. Both UV-A and catalyst were necessary for the degradation of this molecule. 
Higher pollutant abatement and total organic carbon conversion were achieved when the initial pollutant concentration decreases. It was also observed that photocatalytic elimination was significantly affected by the initial solution $\mathrm{pH}$ and catalyst load. Under acidic $\mathrm{pH}$ conditions, the degradation and mineralization efficiencies were strongly enhanced. Indeed, at $\mathrm{pH} 4$ almost all the dissolved organic carbon was mineralized, achieving an elimination yield of $92 \%$ after $190 \mathrm{~min}$ of irradiation.

The investigation of the inhibiting effect of radical scavengers allowed us to determine their role in the degradation of the target molecule. It was established that hydroxyl radicals as well as photogenerated holes are involved in the photocatalytic oxidation of this molecule. Furthermore, it was observed that the degradation rate decreases when the reaction is conducted in real water samples. The selected support was found to be suitable for photocatalytic applications, showing very good stability through four consecutive catalyst reuse cycles.

Finally, the ecotoxicity data obtained in this work demonstrated a higher toxicity for the initial solution as well as for one of the samples collected at the first stages of irradiation, due to the formation of more toxic reaction byproducts. Moreover, it was proven that the toxicity of the samples collected after 190 min of irradiation was significantly reduced, confirming the detoxification efficiency of this process.

Overall, our findings demonstrated that the photocatalytic process using UV-A and titanium nanosized catalysts can be a potential technique for the destruction and toxicity elimination of biorefractory emergent water contaminants.

Author Contributions: Conceptualization, N.V., R.M.H., A.I.S., I.F.-K. and L.F.; Formal analysis, L.R., I.F.-K. and L.F.; Investigation, N.V., N.B. and L.F.; Methodology, N.V., L.R., I.F.-K. and N.B.; Resources, A.I.S. and N.B.; Software, R.M.H. and A.I.S.; Supervision, R.M.H., A.I.S., L.R. and L.F.; Validation, N.V., R.M.H., A.I.S., L.R., I.F.-K., N.B. and L.F.; Writing-Original draft, N.V., R.M.H. and L.F.

Funding: This research was funded by “Lucian Blaga” University of Sibiu, grant number LBUS-IRG-2016-02.

Acknowledgments: Project financed by “Lucian Blaga” University of Sibiu Research Grants LBUS-IRG-2016-02. L. Favier and I. Fekete-Kertész are grateful to the bilateral French-Hungarian project PHC BALATON No. 38644SF for the mobility grants.

Conflicts of Interest: The authors declare no conflict of interest.

\section{References}

1. Mestre, A.S.; Nabiço, A.; Figueiredo, P.L.; Pinto, M.L.; Santos, M.S.C.; Fonseca, I.M. Enhanced clofibric acid removal by activated carbons: Water hardness as a key parameter. Chem. Eng. J. 2016, 286, 538-548. [CrossRef]

2. Tsiampalis, A.; Frontistis, Z.; Binas, V.; Kiriakidis, G.; Mantzavinos, D. Degradation of sulfamethoxazole using iron-doped titania and simulated solar radiation. Catalysts 2019, 9, 612. [CrossRef]

3. Nutescu Duduman, C.; de Salazar y Caso de Los Cobos, J.M.G.; Harja, M.; Barrena Perez, M.I.; Gomez de Castro, C.; Lutic, D.; Kotova, O.; Cretescu, I. Preparation and characterization of nanocomposite material based on $\mathrm{TiO}_{2}-\mathrm{Ag}$ for environmental applications. Environ. Eng. Manag. J. 2018, 17, 925-936. [CrossRef]

4. Semrany, S.; Favier, L.; Djelal, H.; Taha, S.; Amrane, A. Bioaugmentation: Possible solution in the treatment of Bio-Refractory Organic Compounds (Bio-ROCs). Biochem. Eng. J. 2012, 69, 75-86. [CrossRef]

5. Khetan, S.K.; Collins, T.J. Human pharmaceuticals in the aquatic environment: A challenge to green chemistry. Chem. Rev. 2007, 107, 2319-2364. [CrossRef] [PubMed]

6. Popa Ungureanu, C.; Favier, L.; Bahrim, G. Screening of soil bacteria as potential agents for drugs biodegradation: A case study with clofibric acid. J. Chem. Technol. Biotechnol. 2016, 91, 1646-1653. [CrossRef]

7. Hemidouche, S.; Favier, L.; Amrane, A.; Dabert, P.; Le Roux, S.; Sadaoui, Z. Successful biodegradation of a refractory pharmaceutical compound by an indigenous phenol-tolerant Pseudomonas aeruginosa strain. Water Air Soil Pollut. 2018, 229, 103. [CrossRef] 
8. Dordio, A.; Palace Carvalho, A.J.; Teixeira, D.M.; Dias, C.B.; Pinto, A.P. Removal of pharmaceuticals in microcosm constructed wetlands using Typha spp. and LECA. Bioresour. Technol. 2010, 101, 886-892. [CrossRef] [PubMed]

9. Salgado, R.; Noronha, J.P.; Oehmen, A.; Carvalho, G.; Reis, M.A.M. Analysis of 65 pharmaceuticals and personal care products in 5 wastewater treatment plants in Portugal using a simplified analytical methodology. Water Sci. Technol. 2010, 62, 2862-2871. [CrossRef] [PubMed]

10. Tauxe-Wuersch, A.; de Alencastro, L.F.; Grandjean, D.; Tarradellas, J. Occurrence of several acidic drugs in sewage treatment plants in Switzerland and risk assessment. Water Res. 2005, 9, 1761-1772. [CrossRef]

11. Ternes, T.A.; Meisenheimer, M.; McDowell, D.; Sacher, F.; Brauch, H.J.; Haist-Gulde, B.; Preuss, G.; Wilme, U.; Zulei-Seibert, N. Removal of pharmaceuticals during drinking water treatment. Environ. Sci. Technol. 2002, 36, 3855-3863. [CrossRef] [PubMed]

12. Hasan, Z.; Choi, E.-J.; Jhung, S.H. Adsorption of naproxen and clofibric acid over a metal- organic framework MIL-101 functionalized with acidic and basic groups. Chem. Eng. J. 2013, 219, 537-544. [CrossRef]

13. Tan, L.; Shuang, C.; Wang, Y.; Wang, J.; Su, Y.; Li, A. Effect of pore structure on the removal of clofibric acid by magnetic anion exchange resin. Chemosphere 2018, 191, 817-824. [CrossRef] [PubMed]

14. Tang, Y.; Shi, X.; Liu, Y.; Feng, L.; Zhang, L. Degradation of clofibric acid in UV/chlorine disinfection process: kinetics, reactive species contribution and pathways. R. Soc. Open Sci. 2018, 5, 1-13. [CrossRef] [PubMed]

15. Hansen, K.M.S.; Spiliotopoulou, A.; Chhetri, R.K.; Escolà Casas, M.; Bester, K.; Andersen, H.R. Ozonation for source treatment of pharmaceuticals in hospital wastewater-Ozone lifetime and required ozone dose. Chem. Eng. J. 2016, 290, 507-514. [CrossRef]

16. Sable, S.S.; Ghute, P.P.; Fakhrnasova, D.; Mane, R.B.; Rode, C.V.; Medina, F.; Contreras, S. Catalytic ozonation of clofibric acid over copper-based catalysts: In situ ATR-IR studies. Appl. Catal. B Environ. 2017, 209, 523-529. [CrossRef]

17. Klavarioti, M.; Mantzavinos, D.; Kassinos, D. Removal of residual pharmaceuticals from aqueous systems by advanced oxidation processes. Environ. Int. 2009, 35, 402-417. [CrossRef]

18. Kong, X.; Wu, Z.; Ren, Z.; Guo, K.; Hou, S.; Hua, Z.; Li, X.; Fang, J. Degradation of lipid regulators by the $\mathrm{UV} /$ chlorine process: Radical mechanisms, chlorine oxide radical $\left(\mathrm{ClO}^{*}\right)$-mediated transformation pathways and toxicity changes. Water Res. 2018, 137, 242-250. [CrossRef]

19. Sable, S.S.; Panchangam, S.C.; Lo, S.-L. Abatement of clofibric acid by Fenton-like process using iron oxide supported sulfonated-ZrO2: Efficient heterogeneous catalysts. J. Water Process Eng. 2018, 26, $92-99$. [CrossRef]

20. Sires, I.; Arias, C.; Cabot, P.L.; Centellas, F.; Garrido, J.A.; Rodriguez, R.M.; Brillas, E. Degradation of clofibric acid in acidic aqueous medium by electro-Fenton and photoelectro-Fenton. Chemosphere 2007, 66, 1660-1669. [CrossRef]

21. Sirés, I.; Centellas, F.; Garrido, J.A.; Rodríguez, R.M.; Arias, C.; Cabot, P.-L.; Brillas, E. Mineralization of clofibric acid by electrochemical advanced oxidation processes using a boron-doped diamond anode and Fe2+ and UVA light as catalysts. Appl. Catal. B: Environ. 2007, 72, 373-381. [CrossRef]

22. Kim, I.Y.; Kim, M.K.; Yoon, Y.; Im, J.K.; Zoh, K.D. Kinetics and degradation mechanism of clofibric acid and diclofenac in UV photolysis and UV/H2O2 reaction. Desalin. Water Treat. 2013, 52, 6211-6218. [CrossRef]

23. Li, W.; Lu, S.; Qiu, Z.; Lin, K. UV and VUV photolysis vs. UV/H2O2 and VUV/H2O2, treatment for removal of clofibric acid from aqueous solution. Environ. Technol. 2011, 32, 1063-1071. [CrossRef]

24. Doll, T.E.; Frimmel, F.H. Kinetic study of photocatalytic degradation of carbamazepine, clofibric acid, iomeprol and iopromide assisted by different $\mathrm{TiO} 2$ materials-Determination of intermediates and reaction pathways. Water Res. 2004, 38, 955-964. [CrossRef] [PubMed]

25. Serio, S.; Carlos Silva, L.; Melo Jorge, M.E.; Ferreira, S.; Ciriaco, L.; Jose Pacheco, M.; Lopes, A. Environmental application of $\mathrm{Ti} / \mathrm{TiO}_{2}$ anodes prepared by dc-magnetron sputtering: Degradation of Acid orange 7. Environ. Eng. Manag. J. 2018, 17, 2829-2836. [CrossRef]

26. Favier, L.; Simion, A.I.; Rusu, L.; Pacala, M.L.; Grigoras, C.; Bouzaza, A. A removal of an organic refractory compound by photocatalysis in batch reactor-kinetic studies. Environ. Eng. Manag. J. 2015, 14, 1327-1338. [CrossRef] 
27. Marco-Urrea, E.; Radjenovic, J.; Caminal, G.; Petrovic, M.; Vicent, T.; Barcelo, D. Oxidation of atenolol, propranolol, carbamazepine and clofibric acid by a biological Fenton-like system mediated by the white-rot fungus Trametes versicolor. Water Res. 2010, 44, 521-532. [CrossRef]

28. Ismail, L.; Rifai, A.; Ferronato, C.; Fine, L.; Jaber, F.; Chovelon, J.M. Towards a better understanding of the reactive species involved in the photocatalytic degradation of sulfaclozine. Appl. Catal. B: Environ. 2016, 185, 88-99. [CrossRef]

29. Xekoukoulotakis, N.P.; Drosou, C.; Brebou, C.; Chatzisymeon, E.; Hapeshi, E.; Fatta-Kassinos, D.; Mantzavinos, D. Kinetics of UV-A/TiO2 photocatalytic degradation and mineralization of the antibiotic sulfamethoxazole in aqueous matrices. Catal. Today 2011, 161, 163-168. [CrossRef]

30. Bahnemann, W.; Muneer, M.; Haque, M.M. Titanium dioxide-mediated photocatalysed degradation of few selected organic pollutants in aqueous suspensions. Catal. Today 2007, 124, 133-148. [CrossRef]

31. Hapeshi, E.; Achilleos, A.; Vasquez, M.I.; Michael, C.; Xekoukoulotakis, N.P.; Mantzavinos, D.; Kassinos, D. Drugs degrading photocatalytically: Kinetics and mechanisms of ofloxacin and atenolol removal on titania suspensions. Water Res. 2010, 44, 1737-1746. [CrossRef] [PubMed]

32. Fotiou, T.; Triantis, T.M.; Kaloudis, T.; O'Shea, K.E.; Dionysiou, D.D.; Hiskia, A. Assessment of the roles of reactive oxygen species in the $\mathrm{UV}$ and visible light photocatalytic degradation of cyanotoxins and water taste and odor compounds using C-TiO2. Water Res. 2016, 90, 52-61. [CrossRef] [PubMed]

33. Emilio, C.A.; Litter, M.I.; Kunst, M.; Bouchard, M.; Colbeau, J.C. Phenol photodegradation on platinized-TiO2 photocatalysts related to charge-carrier dynamics. Langmuir 2006, 22, 3606-3613. [CrossRef] [PubMed]

34. Hurum, D.C.; Agrios, A.G.; Gray, K.A.; Rajh, T.; Thurnauer, M.C. Explaining the enhanced photocatalytic activity of Degussa P25 mixed-phase TiO2 using EPR. J. Phys. Chem. B 2003, 107, 4545-4549. [CrossRef]

35. Bickley, R.I.; Gonzalez-Carreno, T.; Lees, J.S.; Palmisano, L.; Tilley, R.J.D. A structural investigation of titanium dioxide photocatalysts. J. Solid State Chem. 1991, 92, 178-190. [CrossRef]

36. Berberidou, C.; Kitsiou, V.; Kazala, E.; Lambropoulou, D.A.; Kouras, A.; Kosma, C.I.; Albanis, T.A.; Poulios, I. Study of the decomposition and detoxification of the herbicide bentazon by heterogeneous photocatalysis: Kinetics, intermediates and transformation pathways. Appl. Catal. B Environ. 2017, 200, 150-163. [CrossRef]

37. Ziegmann, M.; Frimmel, F.H. Photocatalytic degradation of clofibric acid, carbamazepine and iomeprol using conglomerated TiO2 and activated carbon in aqueous suspension. Water Sci. Technol. 2010, 61, $273-281$. [CrossRef] [PubMed]

38. Favier, L.; Simion, A.I.; Matei, E.; Grigoras, C.G.; Kadmi, Y.; Bouzaza, A. Photocatalytic oxidation of a hazardous phenolic compound over TiO2 in a batch system. Environ. Eng. Manag. J. 2016, 15, 1059-1067. [CrossRef]

39. Favier, L.; Harja, M.; Simion, A.I.; Rusu, L.; Kadmi, Y.; Pacala, M.L.; Bouzaza, A. Advanced oxidation process for the removal of chlorinated phenols in aqueous suspensions. J. Environ. Prot. Ecol. 2016, 17, 1132-1141.

40. Meng, Y.; Wang, Y.; Qi, H.; Xue, N.; Sun, Y.; Gao, B.; Li, Q. Trihalomethane (THM) formation from synergic disinfection of biologically treated municipal wastewater: Effect of ultraviolet (UV) irradiation and titanium dioxide photocatalysis on dissolve organic matter fractions. Chem. Eng. J. 2016, 303, 252-260. [CrossRef]

41. Booshehri, A.Y.; Polo-Lopez, M.I.; Castro-Alférez, M.; He, P.; Xu, R.; Rong, W.; Malato, S.; Fernández-Ibáñez, P. Assessment of solar photocatalysis using Ag/BiVO4 at pilot solar compound Parabolic Collector for inactivation of pathogens in well water and secondary effluents. Catal. Today 2017, 281, 124-134. [CrossRef]

42. Lu, N.; Zhao, Y.; Liu, H.; Guo, Y.; Yuan, X.; Xu, H.; Peng, H.; Qin, H. Design of polyoxometallate-titania composite film (H3PW12O40/TiO2) for the degradation of an aqueous dye Rhodamine B under the simulated sunlight irradiation. J. Hazard. Mater. 2012, 199, 1-8. [CrossRef] [PubMed]

43. Silva, C.G.; Faria, J.L. Photocatalytic oxidation of phenolic compounds by using a carbon nanotube-titanium dioxide composite catalyst. Chem. Sus. Chem. 2010, 3, 609-618. [CrossRef] [PubMed]

44. Achilleos, A.; Hapeshi, E.; Xekoukoulotakis, N.P.; Mantzavinos, D.; Fatta-Kassinos, D. UV-A and solar photodegradation of ibuprofen and carbamazepine catalyzed by TiO2. Sep. Sci. Technol. 2010, 45, 1564-1570. [CrossRef]

45. Sarkar, S.; Das, R.; Choib, H.; Bhattacharjee, C. Involvement of process parameters and various modes of application of $\mathrm{TiO} 2$ nanoparticles in heterogeneous photocatalysis of pharmaceutical wastes-A short review. RSC Adv. 2014, 4, 57250-57266. [CrossRef]

46. Affamn, A.C.; Chaudhuri, M. Degradation of pesticides chlorpyrifos, cypermethrin and chlorothalonil in aqueous solution by TiO2 photocatalysis. J. Environ. Manag. 2013, 130, 160-165. [CrossRef] [PubMed] 
47. Gong, H.; Chu, W.; Chen, M.; Wang, Q. A systematic study on photocatalysis of antipyrine: Catalyst characterization, parameter optimization, reaction mechanism and toxicity evolution to plankton. Water Res. 2017, 112, 167-175. [CrossRef] [PubMed]

48. Chen, M.; Chu, W. Degradation of antibiotic norfloxacin in aqueous solution by visible-light-mediated C-TiO2 photocatalysis. J. Hazard. Mater. 2012, 219, 183-189. [CrossRef] [PubMed]

49. Boroski, M.; Rodrigues, A.C.; Garcia, J.C.; Sampaio, L.C.; Nozaki, J.; Hioka, N. Combined electrocoagulation and $\mathrm{TiO} 2$ photoassisted treatment applied to wastewater effluents from pharmaceutical and cosmetic industries. J. Hazard. Mater. 2009, 162, 448-454. [CrossRef]

50. Antonopoulou, M.; Vlastos, D.; Konstantinou, I. Photocatalytic degradation of pentachlorophenol by N-F-TiO2: Identification of intermediates, mechanism involved, genotoxicity and ecotoxicity evaluation. Photochem. Photobiol. Sci. 2015, 14, 520-527. [CrossRef]

51. Antonopoulou, M.; Karagianni, P.; Konstantinou, I.K. Kinetic and mechanistic study of photocatalytic degradation of flame retardant Tris (1-chloro-2-propyl) phosphate (TCPP). Appl. Catal. B Environ. 2016, 192, 152-160. [CrossRef]

52. Silva, C.G.; Wang, W.; Faria, J.L. Photocatalytic and photochemical degradation of mono-, di-and tri-azo dyes in aqueous solution under UV irradiation. J. Photochem. Photobiol. A: Chem. 2006, 181, 314-324. [CrossRef]

53. Fernández-Castro, P.; Vallejo, M.; San Román, M.F.; Ortiz, I. Insight on the fundamentals of advanced oxidation processes. Role and review of the determination methods of reactive oxygen species. J. Chem. Technol. Biotechnol. 2015, 90, 796-820. [CrossRef]

54. Ribao, P.; Corredor, J.; Rivero, M.J.; Ortiz, I. Role of reactive oxygen species on the activity of noble metal-doped TiO2 photocatalysts. J. Hazard. Mater. 2019, 372, 45-51. [CrossRef] [PubMed]

55. Cavalcante, R.P.; Dantas, R.F.; Bayarri, B.; González, O.; Giménez, J.; Esplugas, S.; Machulek, A. Photocatalytic mechanism of metoprolol oxidation by photocatalysts $\mathrm{TiO} 2$ and $\mathrm{TiO} 2$ doped with $5 \%$ B: Primary active species and intermediates. Appl. Catal. B Environ. 2016, 194, 111-122. [CrossRef]

56. Velegraki, T.; Hapeshi, E.; Fatta-Kassinos, D.; Poulios, I. Solar-induced heterogeneous photocatalytic degradation of methyl-paraben. Appl. Catal. B Environ. 2015, 178, 2-11. [CrossRef]

57. Antonopoulou, M.; Giannakas, A.; Deligiannakis, Y.; Konstantinou, I. Kinetic and mechanistic investigation of photocatalytic degradation of the N, N-diethyl-m-toluamide. Chem. Eng. J. 2013, 231, 314-325. [CrossRef]

58. Chen, Y.; Yang, S.; Wang, K.; Lou, L. Role of primary active species and TiO2 surface characteristic in UV-illuminated photodegradation of Acid Orange 7. J. Photoch. Photobiol. A 2005, 172, 47-54. [CrossRef]

59. Palominos, R.; Freer, J.; Mondaca, M.A.; Mansilla, H.D. Evidence for hole participation during the photocatalytic oxidation of the antibiotic flumequine. J. Photoch. Photobiol. A 2008, 193, 139-145. [CrossRef]

60. Hazime, R.; Ferronato, C.; Fine, L.; Salvador, A.; Jaber, F.; Chovelon, J.-M. Photocatalytic degradation of imazalil in an aqueous suspension of $\mathrm{TiO} 2$ and influence of alcohols on the degradation. Appl. Catal. B Environ. 2012, 126, 90-99. [CrossRef]

61. Rizzo, L. Bioassays as a tool for evaluating advanced oxidation process in water and wastewater treatment. Water Res. 2011, 45, 4311-4340. [CrossRef] [PubMed]

62. Migliore, L.; Cozzolino, S.; Fiori, M. Phytotoxicity to and uptake of enrofloxacin in crop plants. Chemosphere 2003, 52, 1233-1244. [CrossRef]

63. Fuentes, A.; Lloréns, M.; Sáez, J.; Aguilar, M.I.; Pérez-Marín, A.B.; Ortuño, J.F.; Meseguer, V.F. Ecotoxicity, phytotoxicity and extractability of heavy metals from different stabilised sewage sludges. Environ. Pollut. 2006, 143, 355-360. [CrossRef] [PubMed]

64. Lofrano, G.; Libralato, G.; Adinolfi, R.; Siciliano, A.; Iannece, P.; Guida, M.; Giugni, M.; Volpi Ghirardini, A.; Carotenuto, M. Photocatalytic degradation of the antibiotic chloramphenicol and effluent toxicity effects. Ecotoxicol. Environ. Safe 2016, 123, 65-71. [CrossRef] [PubMed]

65. Rosal, R.; Gonzalo, M.S.; Boltes, K.; Letón, P.; Vaquero, J.J.; García-Calvo, E. Identification of intermediates and assessment of ecotoxicity in the oxidation products generated during the ozonation of clofibric acid. J. Hazard. Mater. 2009, 172, 1061-1068. [CrossRef]

66. Kadmi, Y.; Favier, L.; Soutrel, I.; Lemasle, M.; Wolbert, D. Ultratrace-level determination of N-Nitrosodimethylamine, N-Nitrosodiethylamine, and N-Nitrosomorpholine in waters by solid-phase extraction followed by liquid chromatography. Open Chem. 2014, 12, 928-936. [CrossRef] 
67. Kadmi, Y.; Favier, L.; Harja, M.; Ionut Simion, A.; Rusu, L.; Wolbert, D. A new strategy for pentachlorophenol monitoring in water samples using ultra-high performance liquid chromatography-mass spectrometry tandem. Environ. Eng. Manag. J. 2015, 14, 567-574.

68. Calvelo Pereira, R.; Monterroso, C.; Macías, F. Phytotoxicity of hexachlorocyclohexane: Effect on germination and early growth of different plant species. Chemosphere 2010, 79, 326-333. [CrossRef]

(C) 2019 by the authors. Licensee MDPI, Basel, Switzerland. This article is an open access article distributed under the terms and conditions of the Creative Commons Attribution (CC BY) license (http://creativecommons.org/licenses/by/4.0/). 